\title{
Beyond Aesthetics: A Study of Teaching Visual Language in the Framework of an Undergraduate Painting Course
}

\section{Ophra Benazon}

In the course of many years of teaching studio courses at an undergraduate level, I have noticed the dialogue which takes place between the students and their work and between the students and myself as they make art objects. This dialogue has concentrated predominantly on formal concerns. Attention to personal experience, or to wider cultural issues, usually arises at a later stage, during the process of reflection on and contemplation of the finished product. Oddly, as if by magic, all the previous concerns regarding the structure of the work disappear at this later stage. Instead, students focus on the content of the painting. Regardless of the weight accorded to the manipulation of the formal elements in the making of an art object, present-day discourse in the visual arts pays little attention to the formal, which is associated with historical formalism. I am assuming that the present negative attitude towards the formal elements of art is part and parcel of a backlash against modernism in general and against some extreme interpretations of "art for art's sake" in particular.

I am concerned that this tendency to diminish the role of the elements in visual art prevents us from acknowledging the contribution of form to expression whether of a personal or of a social nature. I would argue that the handling of the formal properties plays a major role in the artistic process; that a skillful arrangement of formal elements should not be considered as a technique only, but should be acknowledged on its own merit; that a formal analysis of a universal nature can be applied to works of individuals and cultures at all times acknowledging personal and societal characteristics. Although it is commendable that the contemporary visual arts community partakes in and contributes to the present progressive social discourse, one must not neglect the sensual and cognitive aspects of art embedded in the visual elements.

Thus, I devised a course in which students were urged to search and find meaning in the visible elements in painting without borrowing from other disciplines such as philosophy, art history, criticism, sociology, and others. The teaching section took place within a Painting I course offered by the Department of Fine Arts at Bishop's University, Quebec. The-Fine Arts Programme follows the University's liberal arts orientation to impart a general education in art in both its academic and studio manifestations.

I chose to follow Fernande Saint-Martin's semiotics of visual language as a model for a contemporary examination and use of form for a variety of reasons: Saint-Martin's semiotics of visual language proposes an interpretation of form that is explicit, coherent, and directly related to artistic practice. In addition, her approach is multidisciplinary; it is innovative; it proposes new basic units based on a notion of perception that incorporates other senses in addition to vision; it takes into account primary topological relations of proximity, separation, envelopment,

Marilyn Zurmuehlen's Working Papers In Art Education 1998-1999 
and rhythmic succession not subject to mathematical abstraction, thus breaking away from the traditional basic units of line, form, colour, symmetry, balance, and others; it is not based on any aesthetic theory; it takes into consideration personal experience; it leaves room for subjective interpretation; it is not judgmental, yet it does not drift into relativism. Perhaps the most attractive feature of Saint-Martin's interpretation of form is that she does not present the issue of form and content as complementing each other. Instead, she identifies two separate meanings: one derived from the formal constellation of an art work; the other, from the narrative or symbolic content--what she calls the iconic. In her view, the two are not necessarily identical; very often they contradict.

Saint-Martin constructs her theory of visual language using several sources: psychoanalytical theory, Jean Piaget's theory of the human construction of representation, the Gestalt theory of perception, and the linguistic branch of the semiotics of art.

A psychoanalytical approach enables Saint-Martin to make a direct connection between the bodily senses and the experience of space embedded in visual language. Bodily senses and the experience of space are distinct and generally opposed to verbal language. This approach makes it possible for one to draw meaning from pictorial elements such as shapes, colors, and textures, regardless of what they depict in terms of the everyday familiar objects, ideas, symbols, or messages that these elements may convey.

Saint-Martin points to the close similarity between the variety of space arrangements devised by mature painters and the spaces that children naturally exhibit in their drawings and paintings at various stages of their development. Elasticity and continuity are the main characteristics of these spaces as they appear in children's as well as in artists' paintings. The early experience of space is of a Topological nature: it is of a two-dimensional nature; it excludes threedimensional projective space because the latter disrupts the continuity by creating empty space. Topological space is first experienced in the close relation between an infant's movements and the objects that lie within immediate reach, especially between her/himself and the mother's body. Children can graphically produce forms known to them from touch only, without ever having been visually exposed to them.

Saint-Martin makes a link between topological space and the gestalt perception theory. In her view the regrouping process that takes place in producing a gestalt takes place at a lower level of the perceptual organization, in the realm of topological relationships. Saint-Martin argues that gestalt theory of perception, contrary to its negative reputation in some art circles, embraces a holistic and a dialectical method in the examination of phenomena, leaves room in its "good form" for personal and cultural interpretations, is open to systems of values in human behavior, and does not purport to have a recipe for a universal good form.

The gestalt theorists postulates that the same mechanism that is at work in the structure of the external field also operates in the physiological and

Marilyn Zurmuehlen's Working Papers In Art Education 1998-1999 
psychological realm. Both are produced in an energy-laden field, in which forms mutually adjoin, oppose, and transform. This mechanism is flexible, allowing for expansion and contraction. The perceptual process depends on the duration of the viewing process of forming visual gestalt and the emotional and cognitive baggage that the perceivers brings to it. In the process of administering multiple eye centrations the perceiver experiences changes in the appearance of the object and its components. The visual field thus becomes a dynamic place, subject to continuous transformations without an actual displacement or change of elements in the external field. Consequently, the perception and apprehension of works of art differ among individual perceivers.

Saint-Martin proposes a Freudian interpretation to the process of visual gestalt forming. In her view, the search for good form is driven by the "principle of pleasure" stemming from a wish to resolve tension. As long as the excitation does not exceed the individual's tolerance level, she/he will experience gratification when the tension dissipates. Through a prolonged examination of an art work, the perceiver experiences mild tensions caused by what she/he perceives as not integrated forms, which she/he continuously subverts into good forms in the service of pleasure. The tension in the perceptual field tends to arise from the observation of open, odd, and out-of-context forms; sharp contrasts among the visual variables such as color, texture, shape, dimension; fragmented geometrical forms or objects of the external natural world; unfamiliar perspectives, projection of different perspectives in the same visual field; and other irregularities. The viewer in these cases completes the forms according to memorized gestalts to restore balance and to experience pleasure. The perceiver constantly oscillates between a bad gestalt and its comparison to and subversion into a good gestalt. Good or bad gestalts are not carved in stone since they are affected by cultural as well as individual preferences, and as such they cannot serve as a foundation for a system of value in an aesthetic theory. The core of the thesis consists of a description and interpretation of the dialectical interaction between the two types of meaning: the one derived from the pure visual elements, the other from the narrative or symbolic order.

Consequently 1 devised a painting course that would enable me to test the validity of Saint-Martin's visual language in my teaching practice. During the course I gave priority to visual language over verbal language by reaffirming the significance of the formal elements of painting. In the choice of the painting projects and in the discussions on the finished work, lengaged the students in a specific practice: how to search and find meaning in the visible elements in images on a flat surface. The students participated in painting projects, discussions on their finished paintings, analysis of paintings along the lines of selected aspects of Saint-Martin's visual language, written assignments on selected exhibitions, and a final take-home exam.

Except for the first introductory project, the majority of the painting projects were designed to prod students to use materials and visual variables such as form, color, texture, etc. as a starting point and inspiration for their paintings; to raise awareness of how the shape and size of the pictorial surface (the Basic Plane) affect the evolution of the painted image; and to explore the

Marilyn Zurmuehlen's Working Papers In Art Education 1998-1999 
expressive character derived from exaggerations and the various perspectives. The last project was a modest attempt to guide students into making a link between the expressive content rooted in visual language and their personal experience.

Students executed ten painting projects:

1. Have you ever been in a situation in which you felt the urge to paint a scene you have observed or imagined? If this is the case, try to fulfill your wish using the materials at your disposal.

2. "A painter takes the sun and makes it into a yellow spot. An artist takes a yellow spot and makes it into a sun" (Picasso). Guided by Picasso's statement, choose a pair of complementary colors using black and white for tonality variations. Create a painting in which the colors determine the content of your work.

3. Create a painting by manipulating masses of painted areas. Proceed from the undifferentiated to the differentiated, i.e., starting from the global and gradually filling in the details. Work simultaneously on the entire painting support.

$4 \& 5$. For the next two paintings, prepare your painting surface by applying a variety of textures using materials to create slight relief effects. Let the texture guide your subject matter. The two projects will be carried out by a) using a variety of suitable materials, b) using acrylic modeling paste.

$6 \& 7$. Inspired by Matisse's cut-out works, prepare large areas of hand-colored sheets of paper; cut them into shapes and assemble them onto a support surface in conformity with a chosen theme. There are two projects: a) an individual collage, b) a group collage.

8 \& 9. Using a life model, create a painting that will reflect your personal interpretation of the person in front of you. The two projects: a) a female model, b) a male model.

On presentation of each painting project, the students received brief instruction on the painting task and on the techniques to be used. Except for the mural, which took two weeks to complete, students worked one week on each project. The students painted mostly during class time, enabling them to interact with fellow students and with me. During the painting period, in addition to reacting to questions addressed to me, I often engaged the students in a dialogue concerning either the work in progress, or on any of their finished work. At the completion of each painting project, students were engaged in a class discussion on their paintings. The discussions focused on: the students;

1. general reactions to the project, or to a particular painting chosen by

2. visual and verbal language and the nature of the interaction between the two;

Marilyn Zurmuehlen's Working Papers In Art Education 1998-1999 
3. contribution of art materials to the production process and to the content of the work, and the link between the materials and the visual language;

4. visual variables and their interaction;

5. structure of the students' work: local (sections of paintings), and global (the entire work);

6. students' satisfaction/dissatisfaction with the results of their work;

7. students' reflection process during and on completion of their work;

8. students' confidence or lack of it in their art production;

9. expression of emotions and pleasure;

10. presence of sensorial manifestations other than sight.

The dialogues with individual students and the class discussions served as the primary source for the description and interpretation of the pedagogical activities throughout the thesis.

In addition to the painting projects, the students executed four written assignments: a short report on their first project, an extensive account of an exhibition of abstract paintings by a professional artist guided by a questionnaire, a short statement on an aspect of the visual language of a painting (individually selected by the students) from an exhibition depicting the human body, and a take-home exam in which students wrote an extensive analysis of one of their paintings.

Parallel to the painting projects and the written reports, the students were systematically introduced to selected aspects of Saint-Martin's visual language. The instruction of the visual language was not directly linked to specific projects; that is, the students were not asked to demonstrate the theory in their paintings. The theoretical instruction was given in ten units spread over the semester:

I developed a research methodology to suit the goal of the thesis: how to teach visual language in an introductory painting course. It is composed of a combination of reflection in action as developed by Donald Schön and phenomenology. I used a branch of phenomenology labelled Phenomenography. The goal of this type of research is spelled out by Ference Marton:

Phenomenography [is] a research specialization aimed at the mapping of the qualitatively different ways in which people experience, conceptualize, practice, and understand various aspects of, and various phenomena in the world around them

("Phenomenography: Exploring ... Conceptions" 178-179).

Marilyn Zurmuehlen's Working Papers In Art Education 1998-1999 
Phenomenography does not describe the world as such or the people who perceive the world. It does, however, pertain to the way people think about the world; it tries to map the "hidden world of thoughts"

("Phenomenology: Exploring . . . Conceptions" 179-180).

An analysis of the data collected over the course duration yielded the following observations:

1. The meanings derived from the visual elements and those extracted from the narrative or representation of objects of the natural objects are closely interwoven. A special effort was required in order to separate one from the other. In most cases, the mimetic elements prevailed over the pure visual ones. However, there were numerous cases in which the two were interchangeable; students used the term "sky" to express concerns over a particular shade or tint of blue and talked about blue when they attempted to represent a certain sky effect.

2. Students used their acquired knowledge of visual language to execute preconceived images and vice versa; they gave a narrative interpretation to images originated in visual language. For example, L., who painted a face over the entire painting surface, posed the question of "how to show that the right side of the face is a lot closer than the left side." L. was guided by what she had learned about the phenomenon of depth perception in two-dimensional surfaces: color contrasts, textural treatments (flat areas tend to advance), dimension (larger areas appear closer than small ones), and position on the basic plane (open forms bordering on the peripheries and corners jut forward). L. never commented on the face distortions that ensued from her use of the visual strategies. On the other hand, J., carried away by the treatment of a large blue and green surfaces, was faced with an image which did not quite correspond with his preconceived idea. He consequently changed the story rather than the image. Reflecting on his painting, J. commented:

I could not decide if the scene is of an early morning, because the water wasn't dark or light. I didn't want it to be right in the middle of the day, because I didn't want too bright colors. I can't determine if it's early evening or really early morning, like pre-dawn.

3. In general, over the semester, the students' comments during the work period and on completion of their assignments reflect a steady progress in attention to and understanding of visual language and its expressive and affective characteristics. It turned out that a course that aimed at teaching the formal elements in painting ended up closely related to the self-expression aesthetic. Perhaps the dealing with the formal elements of art is not as dry and remote from life after all. 


\section{References}

Marton, Ference. "Phenomenography: Describing Conceptions of the World Around Us." Instructional Science 10 (1981): (177-200).

Marton, Ference. "Phenomenography: Exploring Different Conceptions of Reality." Qualitative Approaches to Evaluation in Education. Ed. David M.Fetterman. New York: Praeger, 1988. (176-205).

Saint-Martin, Fernande. Sémiologie du langage visuel. Québec: Presses De I'Université du Québec, 1987.

Saint-Martin, Fernande. "L'inscription du sujet thymique dans l'énonciation visuelle." Discours sociallSocial Discourse 2.1-2, (Spring-Summer 1989): 121-28.

Saint-Martin, Fernande. Les fondements topologiques de la peinture. Québec: Bibliothèque québécoise, 1989.

Saint-Martin, Fernande. La théorie de la gestalt. Québec: Presses de I'Université du Québec, 1990.

Saint-Martin, Fernande. The Semiotics of Visual Language. Bloomington: Indiana University Press, 1990.

Saint-Martin, Fernande. "Sémiologie psychanalytique et esthetique." De l'interprétation en arts visuels. Ed. Nycole Paquin. Montréal: Les éditions Triptyque, 1994.

Schön, Donald A. The Reflective Practitioner: How Professionals Think in Action. New York: Basic Books, Inc., 1983.

Schön, Donald A. The Design Studio: An Exploration of its Traditions and Potentials. London: RIBA Publications, 1985.

Schön, Donald A. Educating the Reflective Practitioner. San Francisco, London: Jossey-Bass, 1988. 
Ophra Benazon and Artwork



Figure 1. Painting: Acrylic on canvas, 1971,40" x 40"

All Rights Reserved 


\section{Ophra Benazon and Artwork}

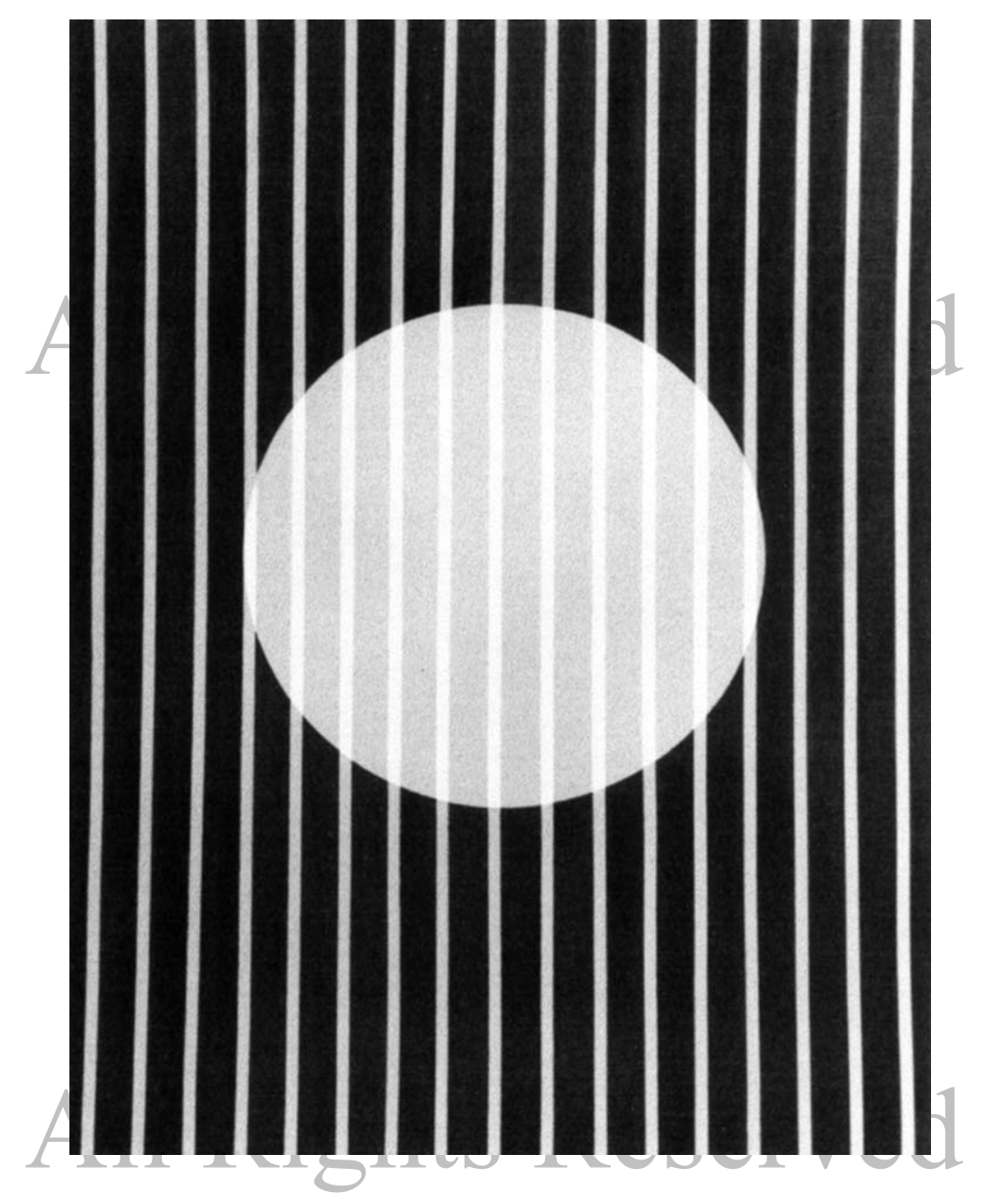

Figure 2. Painting: Acrylic on canvas, 1971, 40" x 60" 


\section{Ophra Benazon and Artwork}

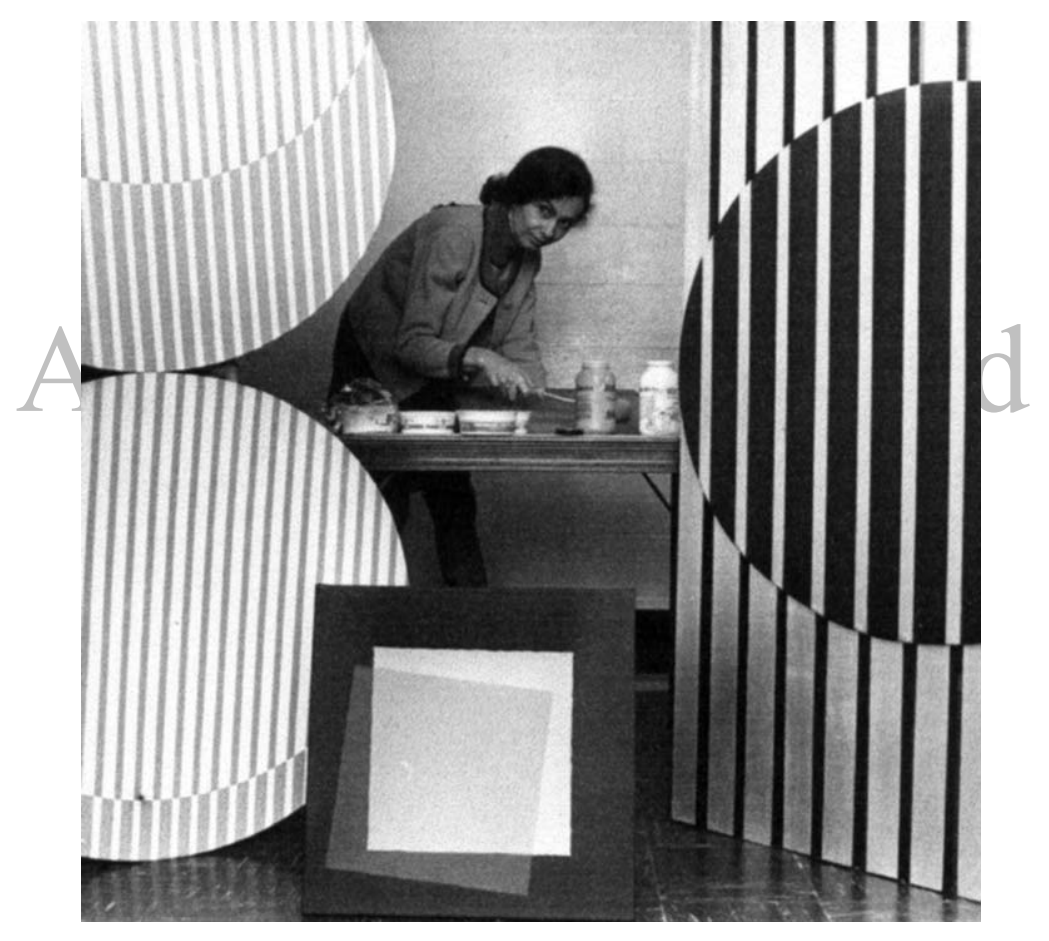

Figure 3. Painting: Ophra Benazon with paintings, 1973

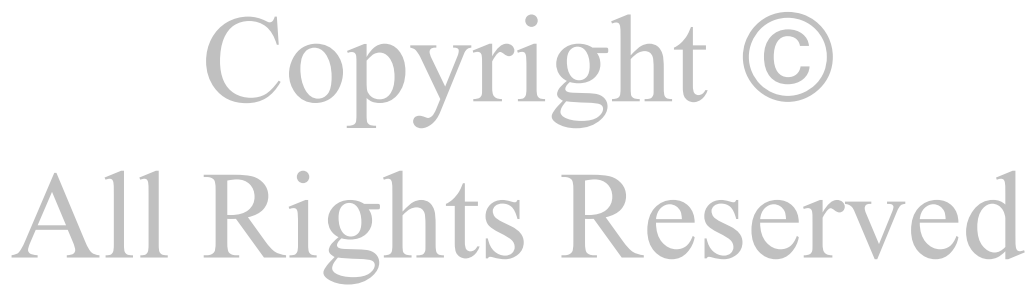

